\title{
Effectiveness of postal smoking cessation advice: a randomized controlled trial in young men with reduced FEV1 and asbestos exposure
}

\author{
S. Humerfelt*, G.E. Eide*, G. Kvåle**, L.E. Aarø+, A. Gulsvik*
}

Effectiveness of postal smoking cessation advice: a randomized controlled trial in young men with reduced FEVI and asbestos exposure. S. Humerfelt, G.E. Eide, G. Kvåle, L.E. Aarø, A. Gulsvik. OERS Journals Ltd 1998.

ABSTRACT: There have been few community-based randomized, controlled intervention trials for cessation in high-risk smokers. In such a trial we evaluated the effects of postal smoking cessation advice in smokers with asbestos exposure and/or reduced forced expiratory volume in one second (FEV1).

All men aged 30-45 yrs $(n=22,392)$ living in 34 municipalities in western Norway were invited to a cross-sectional community survey. Information on smoking habits and occupational asbestos exposure were obtained from self-administered questionnaires and measurements of FEV1 were performed with dry-wedge bellow spirometers. Among 16,393 participants we identified a group of 2,610 smokers with previous occupational asbestos exposure and/or adjusted FEV1 in the lowest quartile. A random half $(n=1,300)$ received a mailed personal letter from a respiratory physician with a person-specific health advice to quit smoking and a pamphlet on smoking cessation. The remaining smokers $(n=1,310)$ acted as controls and did not receive any information.

Twelve months after the intervention, information on smoking habits was re-examined using a postal questionnaire. Among the respondents $(\mathbf{n}=\mathbf{2 , 2 8 2})$, smoking cessation was reported altogether by $13.7 \%$ in the intervention group versus $9.9 \%$ in the control group $(p<0.01)$. The 1 yr sustained quit rate (no smoking at all during the last year) was 5.6 versus $3.5 \%(\mathrm{p}<0.05)$, respectively. Measurements of carbon monoxide in expired air (with ð10 parts per million) confirmed self-reported nonsmoking in samples of the two groups.

In a community this simple postal smoking cessation advice from a respiratory physician based on person-specific risk factors improved the 1 yr sustained success rate by $60 \%$ in identified high-risk smokers.

Eur Respir J 1998; 11: 284-290.
Depts of *Thoracic Medicine, **Epidemiology and +Research Centre for Health Promotion, University of Bergen, Norway.

Correspondence: S. Humerfelt

Dept of Thoracic Medicine

Haukeland Sykehus

N-5021 Bergen

Norway

Fax: 4755975149

Keywords: Biochemical validation community survey randomized controlled trial smoking cessation

Received: December 101996 Accepted after revision October 251997

The trial was supported by grants from the Research Council of Norway. Norwegian Cancer Society, Borregaard A/S, Glaxo Norway A/S and Confederation of Norwegian Business and Industry.
Smoking cessation has beneficial effects on morbidity and mortality from obstructive lung disease (OLD) and lung cancer [1-3]. After smoking cessation, subjects at risk for OLD will reduce the rate of decline in forced expiratory volume in one second (FEV1) to that of never-smokers [4, $5]$, and respiratory symptoms will improve [6, 7]. Quitting smoking in asbestos-exposed individuals is particularly important due to the interaction between asbestos and cigarette smoking in the development of lung cancer $[8,9]$.

Minimal smoking interventions include written or verbal advice with or without information letters, pamphlets, books or maintenance programmes given individually or in groups [10-13]. There have been very few communitybased intervention trials using randomization, control groups and biochemical validation of outcome in subjects at risk for OLD [14, 15].

Respiratory physicians have great responsibilities in smoking cessation, both to their individual patients and the community [16]. In a community it was unknown whether postal smoking cessation advice from a respiratory physician could be successful in young adult males at high-risk for lung cancer and OLD. The primary aim of this randomized controlled trial was to evaluate the effectiveness of such an advice in male smokers who had attended a spirometry survey. The secondary aims were to evaluate whether information to the smoker on the presence of reduced FEV1 and the harmful effects from asbestos had any additional effects on smoking cessation. Furthermore, we wanted to identify other possible predictors of smoking cessation.

Subjects and methods

\section{Initial survey}

This trial was performed in a sample of men aged 3045 yrs living in 34 rural municipalities in western Norway and who participated in a cross-sectional community survey from October 1988 to October 1989 [17]. All men aged $30-45$ yrs $(n=22,392)$ in this area were invited to the survey with $73 \%$ attendance $(n=16,393$; table 1$)$. Information on smoking habits and previous occupational asbestos 
Table 1. - Age, height, daily cigarette consumption and standardized residuals of $F E V_{1}$ in all subjects aged 30-45 yrs participating in the initial cross-sectional survey and in current smokers with either self-reported previous occupational asbestos exposure (OAE), reduced FEV 1 or both $(n=3,384)$

\begin{tabular}{lcccc}
\hline & All participants & \multicolumn{3}{c}{ Current smokers } \\
\cline { 3 - 5 } & $(\mathrm{n}=16,393)^{\dagger}$ & $\begin{array}{c}\text { OAE } \\
\text { Noduced FEV } 1 \\
(\mathrm{n}=1,558)\end{array}$ & $\begin{array}{c}\text { No OAE } \\
\text { Reduced FEV } 1 \\
(\mathrm{n}=1,293)\end{array}$ & $\begin{array}{c}\text { OAE } \\
\text { Reduced FEV1 } \\
(\mathrm{n}=533)\end{array}$ \\
\hline $\begin{array}{l}\text { Age yrs } \\
\text { Height cm }\end{array}$ & $38 \pm 4$ & $37 \pm 4$ & $37 \pm 4$ & $37 \pm 4$ \\
Cigarettes·day ${ }^{-1} \mathrm{n}$ & $179 \pm 6$ & $178 \pm 6$ & $180 \pm 6$ & $179 \pm 7$ \\
$\quad 1-9$ & $1012(6)$ & $193(12)$ & $157(12)$ & $66(12)$ \\
$10-19$ & $3871(24)$ & $880(57)$ & $712(55)$ & $278(52)$ \\
Š20 & $2098(13)$ & $485(31)$ & $424(33)$ & $189(36)$ \\
SFEV1 & $-0.380 \pm 0.95+$ & $-0.112 \pm 0.62$ & $-1.642 \pm 0.60$ & $-1.624 \pm 0.57$ \\
\hline
\end{tabular}

Values are mean $\pm S D$, or absolute number with percentage in parenthesis. Reduced FEV1 was defined as an age- and height-adjusted FEV1 in the lowest quartile of all attendants. $\div$ : All participants included also 5,021 (31\%) never-smokers and 4,116 (25\%) exsmokers as well as $275(2 \%)$ subjects with missing information on smoking habits; +: Calculated in 13,930 subjects with three acceptable spirometric recordings. FEV1: forced expiratory volume in one second; SFEV1: standardized residual of FEV1.

exposure was obtained from a self-administered questionnaire [18] and measurements were performed of height, weight and spirometry in all attendants. Forced expirations were recorded using dry-wedge spirometers (Vitalograph S-model; Vitalograph Ltd., Buckingham, UK) [17, 19]. The highest of three FEV1 values were used in the analyses after correcting for body temperature and pressure saturated (BTPS) conditions. Age- and height-adjusted FEV1 levels were calculated using regression coefficients for age and body-height based on the Norwegian reference population of healthy asymptomatic men from the city of Oslo [20]. The regression coefficients used were $-0.032 \mathrm{~L} \cdot \mathrm{yr}^{-1}$ and $5.742 \mathrm{~L} \cdot \mathrm{min}^{-1}$, respectively, with a constant of -4.540 and residual standard deviation of $0.549 \mathrm{~L}$. Age- and height-standardized residuals of maximum values of FEV1 (SFEV1) were used as determinants of lung function level [5].

Sample size end subjects included in the randomized controlled trial

When designing this trial we calculated that $1,300 \mathrm{sub}-$ jects (response rate of 70\%) would be necessary in each group in order to detect (alpha $=0.05$; beta $=0.20$ ) [21] a significant difference after 12 months of a $5 \%$ sustained change in the intervention group versus $2.5 \%$ change in the control group [22].

Based on information from all participants who had attended the initial survey by October 1989, we identified a trial population of 3,384 men as high-risk smokers (table 1). They included current smokers with either previous occupational asbestos exposure $(n=1,558)$, an age- and height-adjusted FEV1 within the lowest quartile (reduced FEV1: $n=1,293)$ or both $(n=533)$. In order to obtain the needed sample size, a random $77 \%$ of the 3,384 subjects were drawn, giving 2,610 subjects. These included 1,186 , 1,014 and 410 subjects in the three subgroups, respectively. They were included in a randomized controlled trial where each individual had a $50 \%$ chance of being drawn to the intervention group $(\mathrm{n}=1,300)$ or control group $(\mathrm{n}=$ 1,310), respectively. On January 15, 1990, a letter was mailed from a respiratory physician to the subjects in the intervention group. This postal advice included personspecific health advice to quit smoking and a pamphlet on smoking cessation.

Each letter had name and address of the recipient printed in the same quality as the rest of the letter. The subject was reminded of his specific answers on smoking and asbestos exposure given at attendance to the initial survey as well as the results from his FEV1 measurements. Information was given about the dangers of continued smoking, especially if exposed to asbestos, having a reduced FEV1 or both risk factors. The letter stated that the recipient belonged to a group of subjects at increased risk for smoking-related lung disease. The recipient was therefore strongly advised to quit. Beneficial effects of smoking cessation were stated, and the recipient was encouraged to read the enclosed pamphlet produced by the Norwegian Cancer Society. Each letter was individually and personally signed by the physician. The pamphlet: "How to become an exsmoker", sized $10 \mathrm{~cm}$ by $14 \mathrm{~cm}$ in 15 pages, emphasized behavioural modification techniques in smoking cessation and recommended an early quit date. The remaining 1,310 subjects acted as controls and did not receive any information. The trial was approved by the Regional Committee of Medical Research Ethics.

\section{Follow-up and validation survey}

In January 1991 all subjects in the intervention group $(\mathrm{n}=1,300)$ and control group $(\mathrm{n}=1,310)$ received a postal self-administered questionnaire with an accompanying letter. Without mentioning the letter given to the intervention group 12 months previously, all subjects were asked to return the questionnaire. If this was not returned, reminder letters were sent 3 and 6 weeks later. The wording on the questions on smoking was identical to that used at the initial survey. Subjects who reported nonsmoking were also asked to give month and year of quitting.

Successful smoking cessation was defined as individuals who at follow-up denied daily smoking. These subjects living in 11 neighbouring municipalities of Bergen included 60 subjects from the control group and 73 from the intervention group. These 133 subjects were, in June 1991, 
invited to a free-of-charge consultation by a respiratory physician. They were invited in a random order with the physician blinded with respect to which group each subject belonged to. Altogether, 114 subjects $(86 \%)$ attended this validation survey. Carbon monoxide (CO) in expired air was measured using a Bedfont EC50 analyzer (Bedfont Technical Instruments Ltd., Upchurch, Sittingbourne, UK) $[23,24]$. In subjects claiming nonsmoking, a cut-off value of $\partial 10$ parts per million ( $\mathrm{ppm}$ ) was used to distinguish nonsmokers from smokers [25].

\section{Statistical methods}

All analyses were performed using the Biomedical Data Programs (BMDP) package (BMDP Statistical Software Ltd., Los Angeles, USA) [26]. Bivariate associations between response and possible predictor variables were tested by chi-squared tests. Odds ratios (ORs) from stratified tables were tested by the Mantel-Haenszel technique. Unpaired t-tests were used to compare mean values. A significance level of $\mathrm{p}=0.05$ (two-tailed) was used. The primary response variable was chosen to be smoking status at follow-up. Linear regression analysis was used to relate daily cigarette consumption at follow-up to cigarette consumption at the initial survey. Multiple logistic regression analysis was applied to relate smoking status at follow-up to possible predictors and their interactions with the postal advice.

\section{Results}

The trial population included $21 \%$ of all participants from the cross-sectional survey and $47 \%$ of all attending smokers (table 1). Subjects identified in the three subgroups of the trial population had similar age and body-height as all participants at the initial survey. Similar daily cigarette consumption was observed within the three subgroups (mean \pm SD: $16 \pm 7$ cigarettes $\cdot$ day $^{-1}$ ). This was on average two cigarettes more per day than among all participating smokers (mean \pm sD: $14 \pm 7$ cigarettes $\cdot$ day $^{-1} ; \mathrm{p}<0.05$ ). The prevalence of self-reported occupational asbestos exposure in this community of men aged 30-45 yrs was 25\% (19\% low, 5\% medium end $1 \%$ high level of exposure) versus $62 \%$ in the trial population (table 1).

Subjects in the intervention group and the control group were well balanced regarding the distribution of inclusion criteria, age, age at smoking onset, body-height, daily cigarette consumption, respiratory symptoms and FEV1 level (table 2).

At follow-up, four intervention and three control subjects were dead. Among the remaining subjects the overall response rate after two reminder letters was $87 \%(\mathrm{n}=$ $2,282)$, being lower $(\mathrm{p}<0.001)$ in the intervention group $(83 \%)$ than in the control group (92\%) (table 3). In the former group, the response rate was inversely related to daily cigarette consumption from the initial survey, being 87,84 and $81 \%$ in smokers of $<10$ (light), 10-19 (medium) and Š20 (heavy) cigarettes·day ${ }^{-1}$, respectively. No such trend was present in the control group.

Among the respondents at follow-up, $13.7 \%(n=148)$ in the intervention group versus $9.9 \%(n=119)$ in the control group reported nonsmoking $(\mathrm{p}<0.01)$. These subjects included those who stopped smoking during "run in" and those who stopped thereafter (after January 1, 1990) during
Table 2. - Comparison of the two randomized groups, based on characteristics from the initial survey $(n=2,610 *)$

\begin{tabular}{lcc}
\hline & $\begin{array}{c}\text { Control group } \\
(\mathrm{n}=1,310)\end{array}$ & $\begin{array}{c}\text { Intervention group } \\
(\mathrm{n}=1,300)\end{array}$ \\
\hline Inclusion criteria $\mathrm{n}$ & & \\
$\quad$ Asbestos exposure & $591(45.1)$ & $595(45.8)$ \\
Reduced FEV $^{\dagger}$ & $512(39.1)$ & $502(38.6)$ \\
Both & $207(15.8)$ & $203(15.6)$ \\
Age yrs & $37 \pm 4$ & $37 \pm 4$ \\
Age at smoking onset yrs & $17.1 \pm 2.8$ & $17.2 \pm 2.9$ \\
Height cm & $179 \pm 6$ & $179 \pm 6$ \\
Cigarettes $^{\dagger}$ day $^{-1} \mathrm{n}$ & $15.8 \pm 7.0$ & $15.9 \pm 6.8$ \\
Morning cough $^{+} \mathrm{n}$ & $315(24.9)$ & $331(26.1)$ \\
Morning phlegm $^{+} \mathrm{n}$ & $255(20.4)$ & $237(19.1)$ \\
SFEV $^{\#}$ & $-1.05 \pm 0.95$ & $-1.05 \pm 0.96$ \\
\hline
\end{tabular}

Values are mean \pm SD, or absolute number with percentage in parenthesis. *: Spirometry was available in 1,158 and 1,154 subjects from the control and intervention groups, respectively; $\dagger$ : Age- and height-adjusted FEV1 in lowest quartile of all attendants; +: Information on morning cough and phlegm was missing in 114 and 77 subjects, respectively; \#: see text for calculations of SFEV1. For definitions, see legend to table 1.

the intervention period (table 3). If we assume that none of the nonrespondents at follow-up stopped smoking, the overall cessation rates (with intention to treat) were $11.4 \%$ versus $9.1 \%(\mathrm{p}=0.05)$, respectively. After excluding subjects who stopped smoking during "run in" (32 subjects in each group) the 12 month cessation rates among the remaining respondents in the two groups were $11.1 \%$ (116 out of 1049) versus $7.4 \%$ (87 out of 1169), respectively $(\mathrm{p}<0.01)$. Although the effect from the postal advice was higher in subjects with reduced FEV1 $(\mathrm{OR}=1.7$; $95 \%$ confidence interval $(95 \% \mathrm{CI}): 1.2-2.5)$ than in those with asbestos exposure $(\mathrm{OR}=1.2 ; 95 \% \mathrm{CI}: 0.8-1.7)$, this difference in effect was not statistically significant (Chi-squared test for homogeneity: $\mathrm{p}=0.12$ ).

Figure 1 illustrates self-reported month of smoking cessation in the two groups. After the postal advice was sent in January 1990 a gradual increase in the cessation rate was observed for the first three months (February to April 1990) in the intervention group compared with that in the control group. Thereafter, the excess gained in the intervention group was maintained until the end of follow-up. The 1 yr sustained success rate by March 1991 (no smoking at all during the preceding 12 months) was $5.6 \%$ in the intervention group versus $3.5 \%(\mathrm{p}<0.05)$ in the control group (fig. 1). This corresponds to $60 \%$ improvement in success following the postal advice.

The cessation rates were inversely related to daily cigarette consumption at initial survey (table 3 ). Quitters in the intervention and control groups smoked less at the initial survey and were slightly older at smoking onset $(\mathrm{p}<0.01)$ than those who did not stop with mean \pm SD values being $13 \pm 7$ versus $16 \pm 7$ cigarettes $\cdot$ day $^{-1}$ and $18 \pm 4$ versus $17 \pm 3$ yrs, respectively. Among smokers at follow-up the mean $\pm S D$ daily cigarette consumption in the intervention group was reduced to $14 \pm 9$ versus $15 \pm 9$ cigarettes in the control group $(p<0.05)$. In these subjects the linear regression coefficient for initial daily cigarette consumption as a predictor for consumption at follow-up was lower in the intervention group $(0.69$; SE: $0.03 ; \mathrm{p}<0.001)$ than in the control group (0.77; SE: $0.03 ; p<0.001)$, although these coefficients were not statistically different. 
Table 3. - Smoking status among respondents at follow-up in March 1991 by daily cigarette consumption at the initial survey in 1988-1989 among the control group (C) and intervention group (I) ( $n=2,282)$

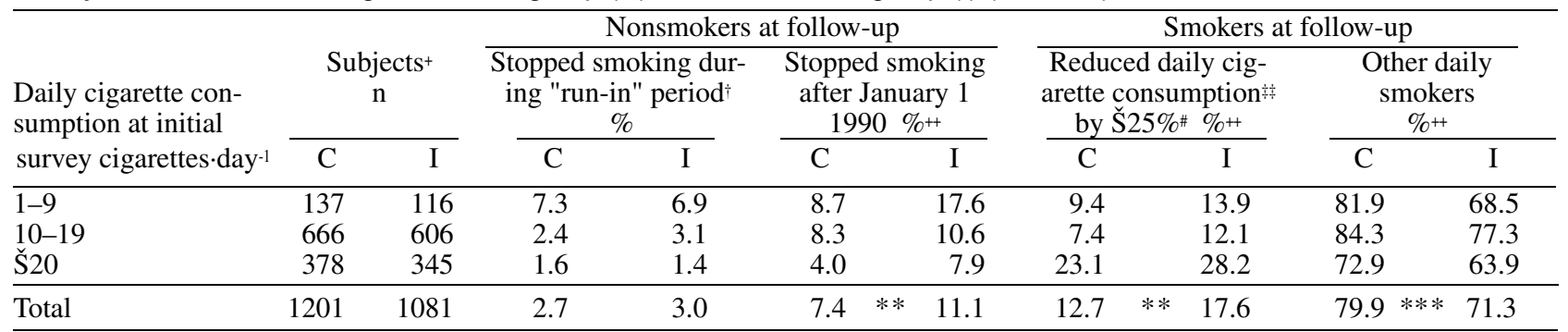

+: Information on cigarette consumption at initial survey was missing in $20(1.7 \%)$ and 14 (1.3\%) subjects in the control and intervention groups, respectively; $\uparrow$ : Stopped smoking prior to January 1, 1990.\#: Reduction in \% related to daily cigarette consumption at initial survey. $* *: \mathrm{p}<0.01 ; * * *: \mathrm{p}<0.001$, significance for the differences observed in outcome at follow-up between the two groups. + : $\%$ related to remaining smokers by January 11990.

Multiple logistic regression analysis was used to estimate the adjusted OR for smoking cessation at follow-up after adjustment for group, age, age at smoking onset, daily cigarette consumption and subgroup of smokers (table 4). The postal advice remained as an independent predictor of smoking cessation. Similar effects were observed in subjects informed on the presence of asbestos exposure, reduced FEV1 or both risk factors. However, older age at smoking onset and low daily cigarette consumption were observed as independent predictors of smoking cessation. No significant first-order interactions were found (no departure from a multiplicative model) from any combinations of the covariables on the risk of smoking cessation.

Similar attendance $(86 \%)$ to the validation survey was observed in samples of the two groups denying nonsmoking at follow-up (table 5). The attendance rates were related to the length of smoking cessation prior to follow-up, being $100 \%$ in the intervention group and $90 \%$ in the control group in those who remained nonsmoking for $\check{\text { S6}} 6$ months (long-term quitters) compared to 69 and 83\%, respectively, in those who had stopped smoking during the last 6 months (short-term quitters) prior to follow-up. At

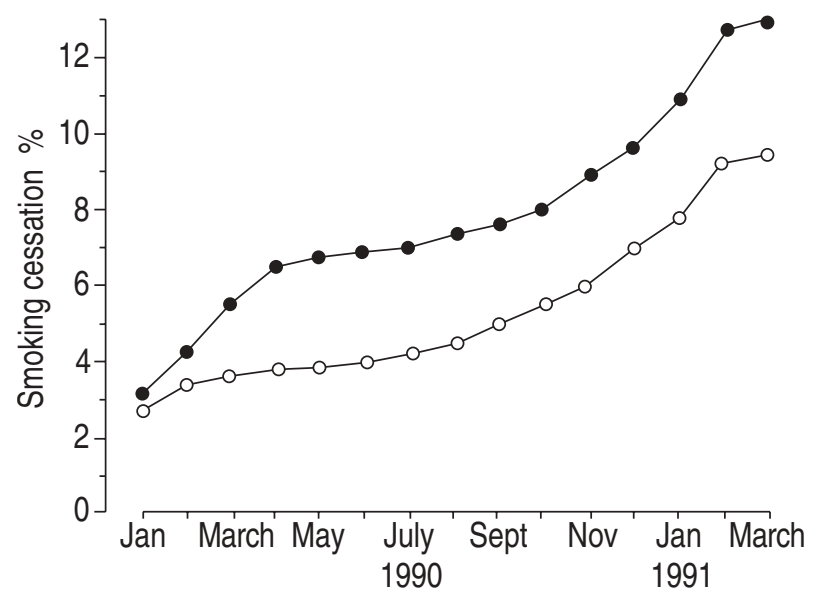

Fig. 1. - Smoking cessation among participants from the intervention group (๑) and from the control group $(\bigcirc)$ by self-reported month of quitting given retrospectively by March $1991(\mathrm{n}=2,282)$. The advice to quit smoking was posted on January 15 1990. Information was missing in nine and seven subjects, respectively. attendance, altogether 24 subjects had relapsed whereas 90 subjects reported nonsmoking (table 5). Higher relapse rates were observed in short-term quitters (being $33 \%$ in the intervention group and $38 \%$ in the control group) than in long-term quitters (being 13 and $18 \%$, respectively; $\mathrm{p}<$ $0.01)$.

Among those claiming nonsmoking in the intervention group $(n=50)$ and in the control group $(n=40)$, a concentration of CO ð10 ppm in expired air was obtained in 49 versus 38 subjects, respectively (table 5). Based on these CO measurements, in June 1991 the cumulative 18 months success rates from January 1990 (after excluding 14 and 17 subjects, respectively, who had quit smoking during "run in") were $6.5 \%$ (35 out of 537) in the intervention group versus $3.6 \%$ (21 out of 589) in the control group $(\mathrm{p}<0.05)$ (table 5).

Table 4. - Adjusted odds ratios (ORs) and 95\% confidence intervals $(95 \% \mathrm{Cl})$ for smoking cessation following the postal advice by intervention group, age, age at smoking onset, daily cigarette consumption and subgroup of smokers $\left(n=2,166^{+}\right)$

\begin{tabular}{llcc}
\hline & \multicolumn{3}{c}{ Nonsmoking at follow-up } \\
\cline { 2 - 4 } Factor & Odds ratio & $95 \%$ CI & p-value \\
\hline Postal advice & 1 & & $<0.01$ \\
$\quad$ No & 1.5 & $1.1-2.0$ & \\
$\quad$ Yes & & & \\
Age yrs & 1 & & \\
$\quad 30-34$ & 0.8 & $0.6-1.2$ & \\
35-39 & 0.9 & $0.6-1.3$ & \\
$\quad 40-45$ & 1 & & $<0.01$ \\
Age at smoking onset yrs & & & \\
$\quad$ X & 1.5 & $1.2-1.8$ & \\
$\quad$ x +5 & & & $<0.001$ \\
Cigarettes-day-1 n & 1 & & \\
$\quad$ 1-9 & 0.6 & $0.4-0.8$ & \\
$\quad$ 10-19 & 0.4 & $0.2-0.6$ & \\
$\quad$ Š20 & & & \\
Subgroup of smokers & 1 & & \\
$\quad$ Asbestos exposure & 0.9 & $0.7-1.3$ & \\
$\quad$ Reduced FEV ${ }^{\#}$ & 0.8 & $0.6-1.3$ & \\
$\quad$ Both & & & \\
\hline
\end{tabular}

+ : Includes all subjects after excluding those with missing information on any of the covariables; : Significance for the independent variable in the model; \#: Age- and height-adjusted forced expiratory volume in one second (FEV1) in lowest quartile of all attendants. 
Table 5. - Validation of self-reported smoking cessation among subjects living in 11 surrounding municipalities of Bergen +

\begin{tabular}{lcc}
\hline & \multicolumn{2}{c}{$\begin{array}{c}\text { Self-reported smoking } \\
\text { cessation using a postal } \\
\text { questionnaire by March 1991 }\end{array}$} \\
\cline { 2 - 3 } & $\begin{array}{c}\text { Control } \\
\text { group }\end{array}$ & $\begin{array}{c}\text { Intervention } \\
\text { group }\end{array}$ \\
\hline Invited for validation in June 91 & $60(100)$ & $73(100)$ \\
Attended validation test & $52(87)$ & $62(85)$ \\
Claimed nonsmoking & $38(63)$ & $49(67)$ \\
CO in expired air d10 ppm & $2(3)$ & $1(1)$ \\
CO in expired air $>10 \mathrm{ppm}$ & $12(20)$ & $12(16)$ \\
Claimed smoking & $3(5)$ & $5(7)$ \\
Telephone informations & $3(5)$ & $5(7)$ \\
Claimed nonsmoking & $2(3)$ & $1(1)$ \\
Claimed smoking &
\end{tabular}

Values are presented as absolute number with percentage in parenthesis. ${ }^{+}$: Answers were obtained from 589 subjects in the control group and 537 subjects in the intervention group. ppm: parts per million.

\section{Discussion}

This randomized controlled trial showed that postal smoking cessation advice from a respiratory physician improved the $1 \mathrm{yr}$ sustained quit rate by $60 \%$ in identified high-risk smokers. This effect appeared to be directly attributable to our intervention. The two groups were well matched at baseline, and assignment to intervention and control groups was completely random. Both groups had identical cessation rates $(3 \%)$ during the "run in" period prior to the intervention with the difference in cessation rates appearing thereafter. Follow-up rates were $>80 \%$ in both groups and the validation survey confirmed the observed higher cessation rate in the intervention group compared with that in the control group.

Selection bias may have affected our results. The response rate at the initial survey was $73 \%$ and the participants had similar demographic characteristics, smoking habits and respiratory symptoms as all men aged 3045 yrs from the general population in Norway [17]. At follow-up, $87 \%$ response was obtained. Similar initial characteristics of age, age at smoking onset, daily cigarette consumption, respiratory symptoms, asbestos exposure and FEV1 level were observed in respondents and nonrespondents from both the intervention and control groups. In agreement with an intervention study in male British civil servants [27], we observed a higher response rate at follow-up in the control group than in the intervention group. One explanation for this difference could be that the follow-up questionnaire was deliberately made impersonal and standardized to avoid pressure on intervention subjects to deny or underestimate continued smoking. Consistent with this we observed that medium and heavy smokers from the initial survey made less effort to answer the follow-up questionnaire in the intervention group than in the control group. Thus, higher smoker rates could possibly be present in nonrespondents from the intervention group than in those from the control group. If present, this would reduce the difference between the two groups. If we speculate that the cessation rate in nonrespondents from the control group $(n=109)$ was $9.9 \%$ (identical to the observed success rate in the respondents) and in those from the intervention group $(n=219)$ two thirds of this $(6.6 \%)$, the overall success rates would have been 9.9 versus $12.5 \%$ $(\mathrm{p}<0.05)$, respectively. From this it seems unlikely that response bias will change our main conclusions of a statistically significant effect from the intervention.

Previous intervention trials have shown that smoking cessation based on self-reports need to be interpreted conservatively due to a high implicit demand on subjects to report positive change [28]. However, this bias in outcome assessment is unlikely to have had considerable influence on our results since we observed good agreement between self-reported smoking cessation and objective $\mathrm{CO}$ measurements in subjects from both groups. Similar observa- tions have previously been observed in asbestos-exposed Norwegian men aged 45-65 yrs who participated in a smok-ing cessation programme [25]. Furthermore, our validation survey also showed that the proportion of subjects claiming smoking $(21 \%)$ and nonsmoking with $\mathrm{CO}$ in expired air $>10$ ppm (3\%) was similar in the two groups (table 5). It is therefore unlikely that men from the intervention group may have responded rather more optimistically to the follow-up questionnaire than subjects in the control group. However, our results should be interpreted with some caution as $\mathrm{CO}$ with its short half-life was only measured once in nonrepresentative samples of subjects. In the validation survey we also observed higher relapse rates in short-term quitters than in long-term quitters. This explained the accelerated increase in the self-reported cessation rate that was observed in short-term quitters from both groups (fig. 1), where 35\% subsequently relapsed into smoking.

Previous studies have shown that about one third of all smokers make a serious quit attempt each year [1]. However, more than $95 \%$ of them relapse, whereas a maximum of $5 \%$ succeed, leaving approximately $1.7 \%(33 \times 5 \%)$ as successful sustained quitters after 1 yr [29]. This was observed in the late 1970s in the USA and was half of the $3.5 \% 1 \mathrm{yr}$ quit rate observed in the control group of our trial in 1990-1991 (fig. 1). One reason for this difference could be the recent more positive attitude to smoking cessation in Norway.

The observed effect from our postal advice is difficult to compare with other intervention studies due to differences in intervention programmes, trial populations, length of follow-up and outcome measures. We used a minimal intervention that could easily be implemented elsewhere when performing cross-sectional surveys in high-risk smokers. Postal advice was applied in this geographical area due to long distance between subjects and respiratory physician as well as the large number of subjects at risk in the community. Using our inclusion criteria the trial population included altogether $47 \%$ of all smokers in the community. Subjects included in other community-based intervention studies are usually self-recruited and highly motivated to quit smoking. In our trial, however, all attending smokers fulfilling the inclusion criteria had equal chance of being selected into the trial, thereby also including smokers without any motivation to quit. This reflects the overall modest $1 \mathrm{yr}$ sustained abstinence rate of $5.6 \%$ following our postal advice. Thus, future community studies should also include information on degree of motivation to quit in order to compare success rates between different intervention trials. Since no criterion was set on 
daily cigarette consumption of the subjects in our trial population, only $58 \%$ of the subjects smoked Š 15 cigarettes.day ${ }^{-1}$. This is in contrast to the Lung Health Study [14] and the Collaborative European Anti-smoking Evaluation (CEASE) Trial [15] where only smokers of S10 and S 15 cigarettes $\cdot$ day $^{-1}$, respectively, were included.

The observed 1 yr sustained quit rate in our trial is similar to results from previous minimal intervention studies $[11,30]$. In a previous community-based study using media announcements from the American Lung Association in self-recruited highly motivated smokers, 12 months sustained cessation was obtained in 5\% after having received postal cessation and maintenance manuals, versus $2 \%$ in controls [11]. Thus, community programmes achieve modest effects in terms of the percentage of smokers who actually quit, but quite substantial numbers when one considers all smokers reached and at low cost [30].

In smokers attending their local doctor, brief verbal smoking cessation advice together with a cessation leaflet and a warning about follow-up was more efficient than advice given alone or no advice [22]. These methods gave 12 months sustained abstinence rates of 5, 3 and $1 \%$, respectively. In patients with smoking-related lung disease, a $5 \% 1 \mathrm{yr}$ success was obtained following verbal advice to quit from respiratory physicians [31]. Six subsequent letters of encouragement improved the outcome to $9 \%$. A nurse-conducted advice in a lung clinic gave a $1 \mathrm{yr}$ cessation rate of $3 \%$ versus $1 \%$ in the control group [13].

In agreement with previous intervention studies without the use of nicotine replacement, we observed that the degree of cessation was inversely related to daily cigarette consumption [13, 27, 32]. This is taken as an indicator of the addictive properties of smoking (both psychological and nicotine dependences), making it more difficult for heavy smokers to quit than light smokers $[15,33]$. Neither the letter nor the pamphlet in our trial included any information on the use of nicotine replacement. Attempts to improve our postal advice by including additional information on nicotine dependence and replacement therapy could possibly have improved our success rates $[34,35]$.

Several studies among selected groups have found little impact from the presence of respiratory symptoms on smoking cessation [36]. In a study of 467 coal miners, the presence of chronic respiratory symptoms was inversely related to cessation [37]. Similarly, we observed that respiratory symptoms were less prevalent among subjects who stopped smoking compared with those who did not, although only morning cough and phlegm reached the 5\% level of statistical significance. These effects, however, disappeared after adjusting for cigarette consumption. This suggests that, in subjects with respiratory symptoms, the addictive properties of smoking are more important than the motivation and ability to stop. This is in contrast to subjects with other diseases where the disease onset is more rapid and dramatic (e.g. myocardial infarction) [36].

Respiratory physicians have a great task to care for smokers, especially when they are at high risk [38]. In this community trial a simple and cheap postal smoking cessation advice from a respiratory physician was useful in men identified with increased risk for smoking-related lung disease. Based on our estimates, such a programme could improve the $1 \mathrm{yr}$ sustained success rate by $28 \%$, i.e. a $60 \%$ improvement in $47 \%$ of all smokers in the community.
Acknowledgements: The authors wish to thank the staff at the National Health Screening Service for data collection and making the data file. In particular, they would like to thank I. Stensvold for her excellent work in randomization and identification of the subjects included in this trial. They also thank D. Apollon, E. Grieg ${ }^{\dagger}$, B. Meidell and S. Nilssen for technical assistance and I.A. Campbell for his helpful comments and criticism in the design of the study and preparation of this manuscript. ( ${ }^{\mathrm{E}}$. Grieg has subsequently died).

\section{References}

1. U.S. Department of Health and Human Services. The health benefits of smoking cessation. A report of the Surgeon General. U.S. Department of Health and Human Services, Public Health Services, Office on Smoking and Health, 1990.

2. Tverdal A, Thelle D, Stensvold I, Leren P, Bjartveit K. Mortality in relation to smoking history: 13 years follow-up of 68,000 Norwegian men and women 35-49 years. J Clin Epidemiol 1993; 46: 475-487.

3. Doll R, Peto R, Wheatley K, Gray R, Sutherland I. Mortality in relation to smoking: 40 years observations on male British doctors. BMJ 1994; 309: 901-911.

4. U.S. Department of Health and Human Services. The health consequences of smoking: chronic obstructive lung disease. A report of the Surgeon General. Rockville, MD. U.S. Department of Health and Human Services, Public Health Services, Office on Smoking and Health, 1984.

5. Humerfelt S, Gulsvik A, Skjærven R, et al. Decline in FEV1 and airflow limitation related to occupational exposures in men of an urban community. Eur Respir J 1993; 6: 1095-1103.

6. Gulsvik A. Prevalence of respiratory symptoms in the city of Oslo. Scand J Respir Dis 1979; 60: 275-285.

7. Krzyzanowski M, Robbins DR, Lebowitz MD. Smoking cessation and changes in respiratory symptoms in two populations followed for 13 years. Int J Epidemiol 1993; 22: 666-673.

8. Hammond EC, Selikoff IJ, Seidman H. Asbestos exposure, cigarette smoking and death rates. Ann NY Acad Sci 1979; 330: 473-490.

9. Saracci R. Personal-environmental interactions in occupational epidemiology. In: McDonald JC, ed. Recent advances in occupational health. London, Churchill Livingstone, 1981; pp. 119-128.

10. British Thoracic Society. Comparison of four methods of smoking withdrawal in patients with smoking related diseases. BMJ 1983; 286: 595-597.

11. Davis AL, Faust R, Ordentlich M. Self-help smoking cessation and maintenance programs: a comparative study with 12-months follow-up by the American Lung Association. Am J Public Health 1984; 74: 1212-1217.

12. Fisher EB, Lichtenstein E, Haire-Joshu D, Morgan GD, Rehberg HR. Methods, successes and failures of smoking cessation programs. Annu Rev Med 1993; 44: 481-513.

13. Tønnesen P, Mikkelsen K, Markholst C, et al. Nurse-conducted smoking cessation with minimal intervention in a lung clinic: a randomized controlled study. Eur Respir $J$ 1996; 9: 2351-2355.

14. Anthonisen NR, Connett JE, Kiley JP, et al. Effects of smoking intervention and the use of an inhaled anticholinergic bronchodilator on the rate of decline of FEV1. JAMA 1994; 272: 1497-1505.

15. Paoletti P, Tønnesen P, Rodriguez-Rosin R. CEASE (Collaborative European Anti-smoking Evaluation): a challenging multicentre trial organized by the European Respiratory Society. Eur Respir J 1993; 6: 719-721. 
16. Yernault JC. Smoking and smoking cessation: a major role for the respiratory physician. Eur Respir J 1995; 8: 1633.

17. Humerfelt S, Eide GE, Kvåle G, Gulsvik A. Predictors of spirometric test failure: a comparison of the 1983 and 1993 acceptability criteria from the European Community for Coal and Steel. Occup Environ Med 1995; 52: 547-553.

18. Bakke P, Gulsvik A, Eide GE, Hanoa R. Smoking habits and lifetime occupational exposure to gases or dusts, including asbestos and quartz, in a Norwegian community. Scand J Work Environ Health 1990; 16: 195-202.

19. Nelson SB, Gardner RM, Crapo RO, Jensen RL. Performance evaluation of contemporary spirometers. Chest 1990; 97: 288-297.

20. Gulsvik A. Prevalence and manifestations of obstructive lung disease in the city of Oslo. Scand J Respir Dis 1979; 60: 286-296.

21. Pocock SJ. Clinical trials: a practical approach. Chichester, John Wiley and Sons, 1987; pp. 123-141.

22. Russell MA, Wilson C, Taylor C, Baker CD. Effect of general practitioners' advice against smoking. BMJ 1979; 2: 231-235.

23. Jarvis MJ, Russell MA, Saloojee Y. Expired air carbon monoxide: a simple breath test of tobacco smoke intake. BMJ 1980; 281: 484-485.

24. Irving JM, Clark EC, Crombie IK, Smith WCS. Evaluation of a portable measure of expired-air carbon monoxide. Prev Med 1988; 17: 109-115.

25. Waage H, Silsand T, Urdal P, Langård S. Discrimination of smoking status by thiocyanate and cotinine in serum, and carbon monoxide in expired air. Int J Epidemiol 1992; 21: 488-493.

26. Dixon JW. BMDP Statistical Software Manual. Berkeley, University of California Press, 1990; pp. 1-1385.

27. Rose G, Hamilton PJS. A randomized controlled trial of the effect on middle-aged men of advice to stop smoking. J Epidemiol Comm Health 1978; 32: 275-281.

28. Fisher EB, Haire-Joshu D, Morgan GD, Rehberg H, Rost K. Smoking and smoking cessation. Am Rev Respir Dis 1990; 142: 702-720.

29. Garvey AJ, Bliss RE, Hitchcock JL, Heinold JW, Rosner B. Predictors of smoking relapse among self-quitters: a report from the Normative Aging Study. Addict Behav 1992; 17: 367-377.

30. Flay B. Mass media and smoking cessation: a critical review. Am J Publ Health 1987; 77: 153-160.

31. British Thoracic Society. Smoking cessation in patients: two further studies by the British Thoracic Society. Tho$\operatorname{rax} 1990$; 45: 835-840.

32. Li VC, Kim YJ, Ewart CK, et al. Effects of physician counseling on the smoking behaviour of asbestos-exposed workers. Prev Med 1984; 13: 462-476.

33. Prignot J. Pharmacological approach to smoking cessation. Eur Respir J 1989; 2: 550-560.

34. Tønnesen P, Fryd V, Hansen M, et al. Effect of nicotine chewing gum in combination with group counseling on the cessation of smoking. N Engl J Med 1988; 318: 15-18.

35. Stapleton JA, Russell MAH, Feyerabend C, et al. Dose effects and predictors of outcome in a randomized trial of transdermal nicotine patches in general practice. Addiction 1995; 90: 31-42.

36. British Thoracic Society. Smoking withdrawal in hospital patients: factors associated with outcome. Thorax 1984; 39: 651-656.

37. Ames RG, Hall DS. Smoking cessation among coal miners as predicted by baseline respiratory function and symptoms: a five year prospective study. Prev Med 1985; 14: 181-186.

38. A statement of the Joint Committee on Smoking and Health. Smoking and health: a physician responsibility. Eur Respir J 1995; 8: 1808-1811. 